\title{
O GOLPE DE 1964 E 0 VOTO POPULAR
}

\author{
Luiz Felipe De AlencAstro
}

Na primeira semana de abril de 1964, com o golpe perpetrado no Congresso, Brasília entrou num estado de sideração. A imagem mais evidente da anormalidade que se instalava foi a chegada de militares mineiros. Sentados em ônibus de banco reto, os soldados seguravam seus fuzis no meio das pernas como se fossem guarda-chuvas.

Na Revolução de 1930, tropas gaúchas cavalgaram pela Avenida Rio Branco e amarraram seus cavalos no Obelisco para acabar com a República Velha. A cena tomou cores dramáticas na memória carioca. Gente mais letrada comparava os gaúchos aos cossacos que invadiram Paris em 1815, depois da derrota de Napoleão, e levaram seus cavalos para beber na fonte da Place de la Concorde.

Vista da Rodoviária - onde havia um par de escadas rolantes que, atraindo crianças e adultos, funcionava como uma pequena Disneylândia do Planalto Central —, o episódio da invasão de Brasília pelos militares mineiros foi apenas patético.

Construída às pressas, Brasília tomou emprestado o passado dos que ali vinham morar. Poucos anos antes, não havia na região nem igreja, nem cemitério, nem câmara municipal, bases elementares de

[1] Na sessão do Senado de junho de 1868 ocorreu uma discussão sobre a palavra "recomendar" que revelava o braço de ferro entre o Legislativo e o Executivo escorado no poder Moderador: a "recomendação" dos senadores a respeito das eleições gaúchas seria impositiva ou apenas uma sugestão ao governo? Tendo o visconde de Jequitinhonha, exilado em Paris nos anos 1820 , começado a declinar em francês formas de tratamento significando "recomendação", o barão de Cotegipe exclamou: "Quanto é bom viajar!", 〈http://www.senado.gov.br/publicacoes/anais/asp/IP_AnaisImperio.asp>, 1868, vol. 1, pp. 39-40, 78, 104-5; vol. 2, pp. 26-7, 70-3, 182; aqui, vol. 2, p. 72, acessado em fev. 2014. qualquer ajuntamento colonial nas Américas.

Tal singularidade permite uma curta digressão para situar a ditadura na perspectiva histórica. Counties na América britânica, cabildos na América espanhola e câmaras na América portuguesa constituíram os primeiros órgãos de poder local e regional no Novo Mundo. Foram as câmaras municipais que institucionalizaram a Independência ao reconhecerem em outubro de 1822 o coroamento de Pedro I como imperador. Daí em diante, o processo legislativo provincial ou municipal foi raramente interrompido. Quando o gabinete Zacarias decretou, em 1866, o adiamento das legislativas no Rio de Grande Sul invadido pelas forças paraguaias, o Senado reagiu. Constatando que os paraguaios já haviam sido rechaçados para a margem oriental do rio Uruguai em 1867 , os senadores pediram a imediata realização de eleições na província ${ }^{1}$. Nenhuma oligarquia regional podia ficar de fora do Parlamento. 
Esse sistema descentralizado de dominação -, que chamei alhures de "anarquia oligárquica" - , formado depois das revoluções regenciais pelo pacto entre os poderes regionais e o governo central, engendrou uma consistente tradição parlamentar ${ }^{2}$. Acoplada ao coronelismo, essa prática política não se confunde com tradição democrática, mas se distingue do movimento autoritário centralista característico de países vizinhos.

Para o bem (da política) ou para o mal (da literatura) não há no Brasil nenhum romance equivalente a Facundo no século XIX, nem parecido com El recurso del método ou El otoño del patriarca no século XX. A truculência da ditadura varguista foi camuflada pelo queremismo e pela anistia que Prestes concedeu a Getulio em 1945. Em seguida foi praticamente deletada da memória política em 1951-1954, no mandato fundador do nacional-desenvolvimentismo. Memórias do cárcere (1953) traz traços desse ocultamento. Traz também a frase denunciadora da prisão arbitrária que revela a perenidade do autoritarismo: "Comecei a perceber que as minhas prerrogativas bestas de pequeno-burguês iam cessar, ou tinham cessado"3. "Prerrogativas bestas" explicita a contingência dos direitos individuais. Direitos que podem ser suspensos por tiranetes que atuaram, mutatis mutandis, na perseguição inquisitorial do Brasil colonial, na ditadura Vargas e, mais tarde, no regime de 1964 .

Província com o maior número de deputados no século XIX e em parte do século XX, Minas Gerais sempre teve papel fundamental na articulação política no Congresso. Além disso, Brasília era a capital de $\mathrm{JK}$, no sentido próprio e figurado.

A eleição de Castello Branco pelo Congresso, com o voto e apoio de JK, impondo o pessedista mineiro Alkmin (seu ex-ministro da Fazenda) como vice-presidente, contra o udenista paulista Auro Moura Andrade (que liderara as "Marchas pela Família" e armara o golpe no Congresso), parecia confirmar a ascendência do PSD sobre militares inexperientes. Predominava em meados de 1964 a interpretação que José Serra descreveu num texto recente no Estadão4: o golpe abria um enfrentamento entre o PSD (JK) e a UDN (Lacerda) pela presidência. JK saía na frente apoiado em Alkmin, ganharia a parada e tudo seria como dantes no quartel d'Abrantes. Num artigo do fim do mês de abril de 1964 no Jornal do Brasil, Carlos Castello Branco confirmava que os militares aceitavam a candidatura de JK em 1965, desde que ele não trouxesse de volta à presidência setores ligados a Jango5.

Adiada a eleição presidencial, foi no Congresso que se urdiu a primeira derrota da ditadura em outubro de 1965. Com a vitória dos pes-
[2] A expressão "anarquia oligárquica", cunhada por historiadores oitocentistas franceses para definir a situação da França durante a Guerra dos Cem Anos, foi retomada por Marx para se referir à Polônia do século XVIII.

[3] Ramos, G. Memórias do cárcere. Rio de Janeiro: Editora Record, 2008, 2 vols., vol. 1, p. 31.

[4] Serra, J. "1964: as ilusões do autoritarismo". O Estado de S. Paulo, 9/01/2014.

[5] "O problema político [...] do Sr. Juscelino Kubitschek como candidato à sucessão presidencial de 1965 está hoje colocado de maneira bastante clara. Existe uma pressão militar definida [...], no sentido não de impedir diretamente sua candidatura, mas visando a evitar que ela seja o instrumento pelo qual o Sr. João Goulart e as correntes políticas banidas [...] retornem ao comando da vida pública do País", Coluna do Castello, Jornal do Brasil, 28/04/1964, 〈http:// www.carloscastellobranco.com.br/ sec_busca.php», acessado em jan. 2014. Reunindo as colunas do notável jornalista do período ditatorial, o site constitui uma fonte fundamental. Pouco lida em São Paulo, onde o JB praticamente inexistia, a obra jornalística de Castello ainda não recebeu a consideração que merece. 
[6] Em 1965, só houve eleições em Alagoas, Guanabara, Goiás, Maranhão, Mato Grosso, Minas Gerais, Pará, Paraíba, Paraná, Rio Grande do Norte e Santa Catarina. As eleições (indiretas) sincrônicas de todos os governadores do país começam em 1970. Comentando questões insuficientemente estudadas do período ditatorial, Daniel Aarão Reis Filho sublinha o "apoio da sociedade" aos militares comprovado, segundo ele, pelas "marchas da família com Deus pela Liberdade", os "altos índices de popularidade" do general Médici $e$ as "votações expressivas obtidas pela Arena". Mas não menciona as derrotas eleitorais muito mais expressivas ainda infligidas ao regime e nem sequer assinala a virada de novembro de 1974. Cf. Aarão Reis Filho, D. "Ditadura, anistia e reconciliação”. Estudos Históricos, vol. 23 , n² 45, 2010, pp. 171-86.

[7] Cardoso, F. H. e Lamounier, B. (orgs.). Os partidos e as eleições no Brasil. São Paulo: Paz e Terra, 1975; Lamounier, B. e outros (org.). Voto de desconfiança: eleições e mudança politica no Brasil, 1970-1979. Petrópolis: Vozes, 1980 .

[8] Martins, C. E. "O balanço da campanha". In: Cardoso e Lamounier, pp. 88-9. sedistas Negrão de Lima (RJ) e Israel Pinheiro (MG) nos dois pleitos para governador mais importantes das eleições, JK mostrava seu prestígio e derrotava os candidatos apoiados por Lacerda e por Magalhães Pinto, líderes civis do golpe. A tacada de JK e do PSD abalou a tese, propalada até hoje, de que os golpistas - e a "Revolução de abril" tinham grande apoio popular6.

O regime deu o troco editando o AI-2 e o AI-3 (1966), com as cassações de JK, Lacerda e Ademar de Barros, as restrições ao STF, a extinção dos partidos políticos e as eleições indiretas para governador e prefeito das capitais.

Resta que nas eleições legislativas de 1966 a Arena saiu-se bem. $O$ $\mathrm{MDB}$ obteve maioria apenas nas Assembleias de quatro Estados (AC, GO, PB e Guanabara), onde elegeu também quatro dos 22 senadores escolhidos na ocasião.

Nas legislativas de 1970, a Arena continuou majoritária no país. Note-se que havia então cinco milhões de novos eleitores, $30 \%$ a mais do que em 1966, configurando o maior aumento relativo do corpo eleitoral entre dois escrutínios da história do país. Numa sociedade cada vez mais urbanizada, o MDB vencia nos Estados em que partidos bem implantados haviam sido escanteados pela ditadura. No Rio Grande do Sul (PTB), no Rio de Janeiro e na Guanabara (PTB e PSD), em Goiás (PSD), na Paraíba (PSD) e em Pernambuco, o movimento social se rearticulava. São Paulo, sem Ademar (cassado em 1966) e sem partido hegemônico, deu a vitória à Arena, mas registrou forte aumento dos votos nulos e brancos (35\%).

Aqui residia o fato novo e decisivo: os votos nulos e brancos dobraram no país em números absolutos, passando de 21\% em 1966 para $30 \%$ em 1970. Como demonstraram mais tarde as análises pioneiras coordenadas no Cebrap por Fernando Henrique Cardoso e Bolívar Lamounier, o crescimento dos votos brancos e nulos em 1970 pressagiava a acachapante vitória do MDB em $1974^{7}$.

Entretanto, nada disso era evidente no início dos anos 1970. Na época, o quadro era de desolação política. As greves de Contagem e Osasco (março e abril de 1968), de que se tinha pouca notícia fora de Minas e São Paulo, anunciavam movimentos sindicais que só vingaram mais tarde. Àquela altura, os torturadores campeavam e despontavam os enfrentamentos armados.

Nas municipais de 1972, a Arena obteve largo sucesso, ganhando em $92 \%$ das prefeituras do país. Setores moderados da ditadura chegaram a preocupar-se com o desaparecimento do MDB. Três meses antes das eleições de 1974, conselheiros políticos do regime temiam uma possível evolução para "um sistema de partido único" 8 . 
No mês de novembro veio a grande virada: o MDB vencia nos principais Estados e nas grandes cidades. Sobretudo, o partido emplacava 16 dos 22 senadores eleitos. A Arena só elegia senadores em Estados que, à exceção da Bahia, tinham pouco peso eleitoral (Alagoas, Bahia, Maranhão, Mato Grosso, Pará e Piauí). Vale lembrar que, na ausência de eleições para presidente, governadores e prefeitos das capitais, a votação para o Senado constituía o escrutínio majoritário mais elevado permitido pela ditadura. $\mathrm{Na}$ circunstância, o voto para senador polarizava a oposição ao regime. A queda progressiva do percentual de votos nulos e brancos na eleição senatorial delineava a instrumentalização e a reinvenção do MDB pelo eleitorado oposicionista: 21,2\% em 1966, $27,7 \%$ em 1970 e $15,1 \%$ em 1974. A última cifra representando a taxa mais baixa de todo o período ditatorial.

Tanto o governo como a oposição foram pegos de surpresa pela intensidade do voto contra o regime.

Num texto escrito duas semanas após o fechamento das urnas, em que caracterizava pela primeira vez os resultados das eleições como um "voto plebiscitário" antirregime, a "Coluna do Castello" chegou à conclusão que o Cebrap aprofundaria em 1980 com a análise comparativa dos resultados eleitorais: "O eleitorado votou MDB, independentemente de nomes e do próprio Partido, porqueesse era o caminho certo de dar o seu recado e criar uma força de Oposição ao regime" 9 .

$\mathrm{Na}$ mesma época, um informe da embaixada americana vazado agora no Wikileaks dizia: "Fontes do governo [...] admitem que o governo (incluindo Geisel) foi surpreendido pelas proporções [oposicionistas] do voto, mas o MDB também." ${ }^{\circ}$.

Reflexo longínquo da "anarquia oligárquica" e da tradição parlamentar das décadas precedentes, ainda vigorava em 1974 uma legislação liberal referente à propaganda eleitoral. Elaborada por parlamentares da UDN na Constituinte de 1946 e nos 1950 - quando o partido esteve sempre na oposição ao governo federal - , a legislação garantia a propaganda eleitoral gratuita no rádio e na televisão. Em março de 1974, o governo enquadrou a propaganda na imprensa, onde reinava a censura, mas confirmou duas horas diárias gratuitas aos partidos na TV e no rádio nos dois meses de campanha eleitoral ${ }^{11}$. Em julho de 1976, numa primeira tentativa de colmatar o desastre de 1974, foi editada a "Lei Falcão", pouco antes das municipais. Doravante, a TV e o rádio só podiam divulgar o nome, a foto, o número e o currículo do candidato, como era já o caso na propaganda publicada nos jornais ${ }^{12}$.

Apesar disso, as municipais de 1976 ratificaram o quadro eleitoral de 1974: O MDB ganhava nas grandes e médias cidades e nos maiores Estados do país. Embora nas capitais só houvesse eleições para
[9] "Coluna do Castello", Jornal do Brasil, 29/11/1974. A expressão "voto plebiscitário" para definir os resultados de novembro de 1974 foi retomada mais tarde por Bolivar Lamounier, "O voto em São Paulo 1970-1978", Lamounier, op. cit., p. 17 .

[10] Embaixada Americana, Brasília, 19/11/1974, 〈http://www. wikileaks.org/plusd/cables/ 1974BRASILo8726_b.htmls, acessado em jan. 2014. Os arquivos do Wikileaks sobre o Brasil devem ser apenas de "first clearance", isto é, de primeira filtragem e são incompletos. Informações mais sigilosas não foram copiadas. Mas o material disponível mostra a embaixada dos EUA mais interessada nas transações externas da economia brasileira do que na política interna, mesmo num momento quente como na virada de novembro de 1974.

[11] Para dar mais chances para a Arena, o regime organiza em julho de 1974 a fusão do Rio de Janeiro, único Estado com um governador do MDB (Chagas Freitas, eleito indiretamente em 1970), com a Guanabara, uma das bases do trabalhismo e da oposição ao regime. No processo, a região perdeu três senadores e herdou problemas que entravam até hoje seu desenvolvimento.

[12] Rabello Duarte, C. "A Lei Falcão: antecedentes e impacto". In: Lamounier, op. cit., pp. 173-216. Cf. também 〈http://www12.senado.gov. br/noticias/materias/2006/07/03/ lei-falcao-faz-3o-anos , acessado em jan. 2014 . 
[13] Coluna do Castello, Jornal do Brasil, 27/04/1977, <http://www.carloscastellobranco.com.br/sec_coluna_view.php?id=410 , acessado $\mathrm{em}$ jan. 2014 .

[14] Faria, V. “As eleições de 1974 no estado de São Paulo: uma análise das variações inter-regionais". In: Cardoso e Lamounier,op.cit.,pp. 205-38; ver também Lamounier, "O voto em São Paulo 1970-78”, op. cit., p. 21.

[15] Rios, F. "O protesto negro no Brasil contemporâneo (1978-2010)”. Lua Nova, n 85, 2012, pp. 41-79.

[16] Vidal Luna, F. e Klein, H. S. "Mudanças sociais no período militar 1964-1985" e "Transformações econômicas no período militar 1964-1985". In: Reis Filho, D. A., Ridenti, M. e Patto S. Motta, R. (orgs.). A ditadura que mudou o Brasil: 50 anos dogolpe de 1964. Rio de Janeiro:Zahar, 2014, pp. 66-91 e pp. 92-111.

[17] Para uma análise aprofundada, cf. Rodrigo Patto Sá Mota, "A modernização autoritário-conservadora nas universidades e a influência da cultura política". In: Reis Filho, Ridenti e Patto S. Motta, pp. $48-65$.

[18] Boito Jr., A. O sindicalismo de Estado no Brasil. Campinas/São Paulo: Unicamp/Hucitec, 1991. vereadores, o MDB vencia em São Paulo, no Rio de Janeiro, em Belo Horizonte e Porto Alegre.

Buscando impedir que esses resultados se transformassem em nova vitória da oposição no Senado e, sobretudo, nas eleições diretas de governador previstas para 1978, a ditadura decretou o "Pacote de abril" (1977). O ucasse consistia no adiamento para 1982 das eleições diretas de governador, na criação de um terço de senadores eleitos indiretamente (os "biônicos") e na mudança do quociente eleitoral para o cálculo do número de deputados federais (de agora em diante baseados no número de habitantes e não mais de eleitores).

À primeira vista, o "Pacote de abril" pretendia enraizar o regime autoritário na política tradicional brasileira, mas a manobra foi recebida com ceticismo pelos próprios políticos da Arena. Como registrou a "Coluna do Castello" logo em seguida ao Pacote: "as reformas de abril não satisfizeram aos políticos, e a Arena, que se procurou beneficiar, sente-se frustrada e ameaçada" ${ }^{13}$.

De fato, as eleições de 1978 confirmam a dinâmica antiditatorial inscrita nos escrutínios majoritários a partir de novembro de 1974. Uma análise elaborada por Vilmar Faria mostrou que o voto emedebista era mais forte nas cidades de mais de 30 mil habitantes e nos candidatos disputando o posto mais elevado ${ }^{14}$. Ou seja, a eleição para o Senado polarizava o movimento antiautoritário. O senador representava o prefeito, o governador, o presidente da República, que não podiam ser eleitos pelo voto direto.

Outras campanhas se iniciaram ou foram ampliadas no contexto das eleições pós-74. Em 1975, Therezinha Zerbini funda o Movimento Feminino pela Anistia, e o Movimento Negro Unificado faz em 1978 seu primeiro ato público em São Paulo ${ }^{15}$. O país mudava, em parte por causa das transformações implementadas pelo regime.

Dados das duas primeiras PNADs realizadas de 1973 e 1976 , cuidadosamente analisados por Elza Berquó no Cebrap, mostravam as mudanças profundas em curso na sociedade. Aumentando regularmente desde 1940, a taxa de fecundidade da população brasileira começara a declinar em 1965. Ao mesmo tempo a urbanização se acelerava: em 1950, as cidades reuniam 36\% da população, em 1980 registrou-se o inverso: $64 \%$ já viviam nas cidades e $36 \%$ nas zonas rurais ${ }^{16}$.

Em 1966, havia 180 mil estudantes nas diversas universidades do país; em 1978 eles somavam 1,225 milhão ${ }^{17}$. Armando Boito aponta que, nos piores anos da repressão ditatorial, entre 1968 e 1978, o total de sindicatos oficiais na área urbana aumentou 53,3\%, passando de 2.616 para $4.009^{18}$. Marcelo Ridenti observa que nas regiões rurais houve crescimento mais expressivo ainda. Fundado em 1963 e ampliado em 1967, o Funrural e outras normas de aposentadoria rural 
favoreciam a criação de sindicatos no campo, os quais passaram de 625 sindicatos em 1968 a $1.669 \mathrm{em} 1975^{19}$.

Nas primeiras eleições diretas para governador em 1982, realizadas sob o signo da anistia e do multipartidarismo, a oposição foi vitoriosa em dez Estados, entre os quais os mais importantes da federação (Acre, Amazonas, Espírito Santo, Goiás, Mato Grosso do Sul, Minas Gerais, Pará, Paraná, São Paulo e Rio de Janeiro, onde Brizola emplacava o PDT). Deliberadamente, os dirigentes do MDB concebiam o partido como uma frente ampla destinada a instaurar o "Estado de Direito", sem avançar plataforma programática mais elaborada. A vagueza estratégica era resumida no slogan de sucesso nas campanhas eleitorais "Vote no MDB, você sabe por que!".

O multipartidarismo, a volta dos exilados de 1964, em particular, de Leonel Brizola e Miguel Arraes, assim como o retorno à vida pública de lideranças estaduais anistiadas (Mário Covas em São Paulo, Waldyr Pires na Bahia, Aluísio Alves no Rio Grande do Norte, Mauro Borges em Goiás, Marcello Alencar no Rio de Janeiro, Sereno Chaise no Rio Grande do Sul) e, enfim, a emergência de Lula e do PT geram um quadro partidário mais complexo.

Provisoriamente unidos na campanha das “Diretas Já!", que representaram as maiores manifestações de massa do Brasil e da América Latina, a oposição ao regime se fragmenta a partir das eleições municipais de 1985 e ao longo dos debates da Constituinte.

O mandato único para os postos executivos e a disputa de correntes políticas e gerações diferentes pelo espólio eleitoral do MDB-PMDB produziram clivagens partidárias em todos os Estados. Daí nasceu a emenda do plebiscito sobre o parlamentarismo e o próprio $\mathrm{PSDB}$. De fato, o perfil das lideranças que aderiram ao PSDB coincide com os setores estaduais que perderam o controle do PMDB e, sobretudo, o lugar na chapa pemedebista de candidatura aos postos majoritários.

Os resultados do plebiscito de 1993, com a esmagadora maioria do presidencialismo sobre o parlamentarismo e sobre a grotesca proposta monarquista, assinalam a última vitória da dinâmica presidencialista, da luta pelo voto majoritário, lançada pelo eleitorado no voto para os senadores do MDB em novembro de $1974^{20}$.

Há dez anos, em 2004, foi realizado um congresso sobre os temas dos golpes e contragolpes da política brasileira intitulado "1954-1964-1984", organizado por Marcelo Ridenti e Maria Aparecida de Aquino na USP e na Unicamp. Entre os debatedores havia especialistas que estavam nos seus vinte anos em 1954, alguns que tinham a mesma idade em 1964 e outros na casa dos vinte anos em 1984. A historiografia se cruzava com a memória militante de três gerações. Constatou-se que já existiam centenas de artigos e mais de uma cen-
[19] Ridenti, M. "Debate 64", Siba, 10/02/2014, <http://sibila.com.br/ cultura/sibila-debate-64-marcelo-ridenti/10274>, acessado em fev. 2014 ; idem, "As oposições à ditadura: resistência e integração". In: Reis Filho, Ridenti, Patto S. Motta, op. cit., pp. 30-41.

[20]Alencastro, L.F. "Cultura democrática e presidencialismo no Brasil". Novos Estudos Cebrap, no 35, 1993 , pp. 21-30. 
Recebido para publicação

em xx de outubro de 2013 .

\section{NOVOS ESTUDOS}

CEBRAP

98, março 2014

pp. 5-11 tena de livros dedicados em parte ou inteiramente à ditadura. Hoje, os números aumentaram bastante.

Singularmente, a análise dos resultados das eleições durante a ditadura pouco avançou desde os estudos dos anos 1970 e 1980 já mencionados.

Resta que, de qualquer ângulo que se enfocarem os eventos, de todo modo que se ponderar sobre os fatos, do jeito que se alinharem as estatísticas, não há como evitar a constatação: foi graças ao voto popular que a ditadura foi acuada, batida e, por fim, derrubada.

Luiz Felipe de AlenCASTRO é professor na Universidade de Paris-Sorbonne e professor convidado da Escola de Economia da FGV de São Paulo. 